\title{
Reptiles of the Gobabeb Research and Training Centre
}

\author{
Hayden D. Hedman ${ }^{1}$, Helina M. Alvarez ${ }^{2}$, Gustaf P. Kalifeni Hanghome ${ }^{3}$, Maria Eifler ${ }^{4}$, and Douglas Eifler ${ }^{4}$ \\ ${ }^{1}$ School of Natural Resources and Environment, Ann Arbor, Michigan 48109, USA \\ ${ }^{2}$ United States Fish and Wildlife Service, Sand Lake National Wildlife Refuge, Columbia, South Dakota 57433, USA \\ ${ }^{3}$ Department of Natural Conservation, Polytechnic of Namibia, Windhoek 9000, Namibia \\ ${ }^{4}$ Erell Institute, Lawrence, Kansas 66047, USA
}

Photographs by Maria Eifler.

$\mathrm{T}$

he Gobabeb Research and Training Centre (Fig. 1) is an internationally recognized research station and premiere site for training and research in arid-land biology. The station is located in the Namib Naukluft National Park $\left(23^{\circ} 33^{\prime} 42.61^{\prime \prime} \mathrm{S}, 15^{\circ} 2^{\prime} 30.15^{\prime \prime} \mathrm{E}\right)$ in Namibia. The research center is approximately $100 \mathrm{~km}$ southeast of Walvis Bay (the nearest small town) and $60 \mathrm{~km}$ from the Atlantic Ocean (Schulze 1969). The Namib Desert is an expansive landscape $(2,000 \times 200 \mathrm{~km})$ with Gobabeb situated at the center of three habitats: Dune, gravel plains, and the Kuiseb River corridor. The region's monthly average temperature range is 26-32 ${ }^{\circ} \mathrm{C}$ and daily temperatures sometimes vary by over 10 ${ }^{\circ} \mathrm{C}$ between day and night. Southern Africa exhibits one of the highest concentrations of endemic species in the world, with more than $80 \%$ endemism for some groups of organisms (Goldblatt and Manning 2002), and an estimated 92\% of the more than 300 species of lizards in southern Africa are indigenous (Branch 1999). Among African nations, Namibia ranks second in lizard diversity (125 species), trailing only South Africa (Bauer 1999). At Gobabeb, faunal and floral surveys have been conducted for the last 50 years, providing an extensive database of its rich biodiversity, with 199 known species of plants, 44 mammals (Fig. 2), 195 birds, and 43 reptiles (Henschel et al. 2006).

Gobabeb was founded in 1962 (www.gobabebtrc.org) by the Southern African Museums Association. Since 1998, the Ministry of Environment and Tourism and the Desert Research Foundation Namibia have jointly managed the station. The station supports a vast array of fields of inquiry, ranging from climate and ecology to geomorphology, conservation and restoration, and anthropology and archeology. Gobabeb's visitors include researchers, university groups,

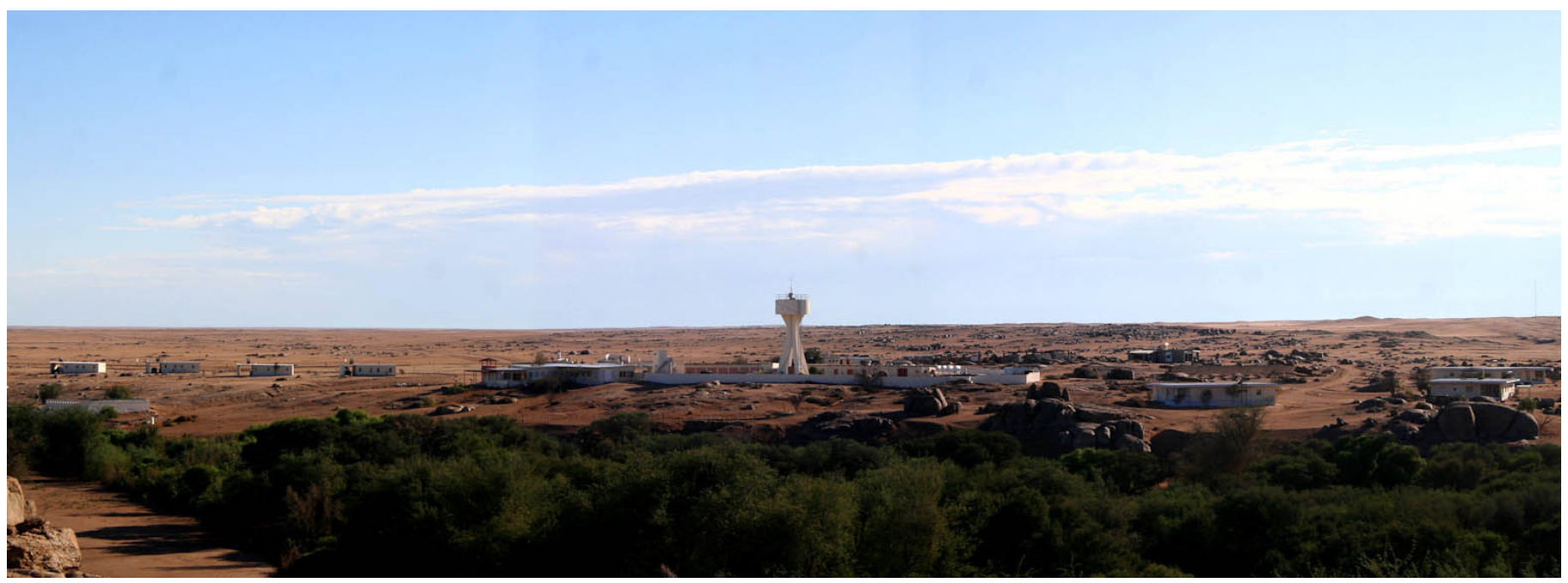

Fig. 1. Gobabeb Research and Training Centre provides tier one resources, as evidenced from hosting over 80 Ph.D. and M.Sc. projects as partnerships both from within Namibia and worldwide. Gobabeb has a helpful staff, including two full-time research technicians and interns available to assist with data collection. Research facilities consist of laboratory space and equipment, rentable storage for long-term use, private and semi-private office space, and an arid ecology library with over 1,800 books, journals, and digitally archived items. 


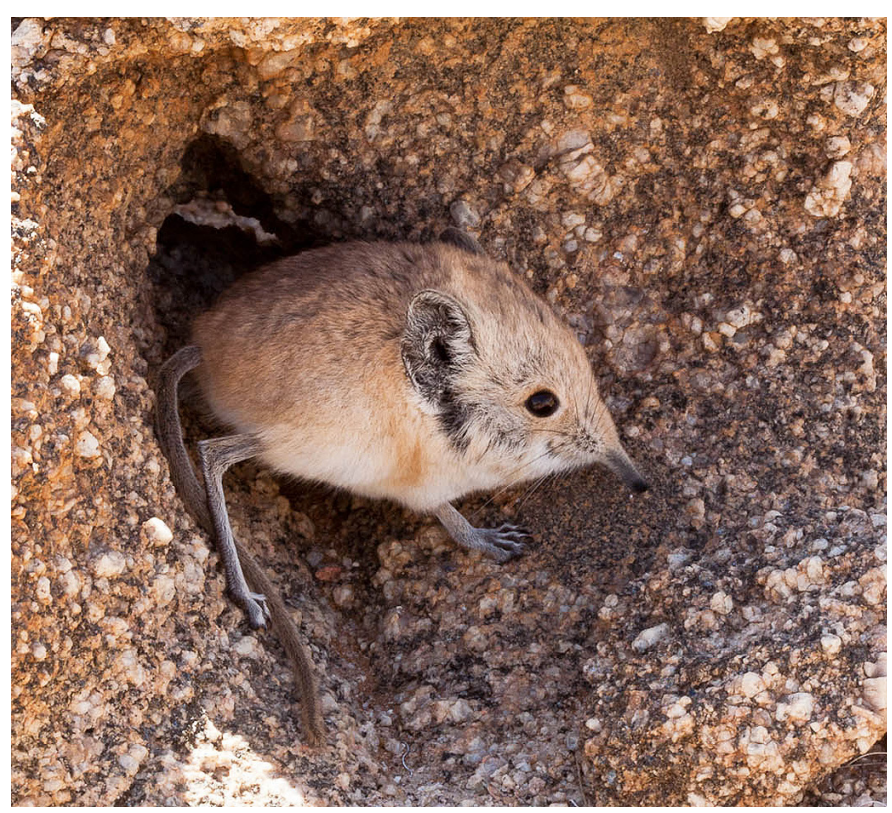

Fig. 2. Nocturnally active Elephant Shrews (Macroscelididae) can be observed throughout the rock outcrops surrounding the station. These small mammals are well adapted to the extreme heat of the desert terrain.

local school groups, students, interns, and tourists, as well as film crews, journalists, and artists. Overall, Gobabeb strives to promote public awareness and knowledge about dry-land ecology and environmental issues.

Our personal investigation was conducted through Erell Institute's International Research Experience for Undergraduates that paired Native American undergraduates with university students from Namibia and Botswana in an intensive, hands-on field research experience focused on the behavioral ecology of Namib Desert lizards.

\section{Living Sustainably in a Fragile Landscape}

Water is a precious commodity in desert environments; getting enough water is a real challenge for organisms that inhabit the Namib Desert, and the array of adaptations seen there is impressive. Although vegetation is scarce, a rare but locally common plant is Welwitschia mirabilis, which gets most of its water from the region's characteristic dew and fog by directly absorbing moisture through the densely packed stomata on its leaves (Middleton 2009). Tenebrionid beetles, as a mechanism to retain fluids and reduce the need to obtain additional water for metabolic functioning, exhibit the lowest transpiration rates of arthropods in the region (Edney 1971).

The Gobabeb Research Centre itself is well designed to conserve water, not unlike the many endemic beetles with their rigid carapaces and other organisms of the region that have evolved adaptations for living in hyperarid conditions. Minimizing water loss though waste removal requires intricate physiological adaptations by most taxonomic groups, which is analogous to Gobabeb's need to mechanically decrease excessive water loss, accomplished through water-conserving toilets and showers. Gobabeb strives to provide a sustainable research environment. For both efficiency and awareness, Gobabeb closely monitors its total monthly resource use, including electricity, gas, and water (www.gobabebtrc.org). The dozens of solar panels erected on the station office, research cabins, and even in open terrain (Fig. 3) harness 100\% of the station's electricity. In total, the station has 72 lead-acid batteries that are charged throughout the day and provide electricity during the evening.

\section{Community at the Station}

The Gobabeb Research Centre community consists of 18 professionals from around the world. The multinational team strives to accommodate researchers, school groups, professional conferences, and visitors from all backgrounds. The community members hold positions (i.e., administrative, research, training, housekeeping, and maintenance) to ensure that research and education can proceed while staying and studying at the center. The majority of the housekeeping and maintenance staff consists of indigenous Africans from the adjacent Topnaar village. The center provides services for research projects but also conducts independent projects and hosts conferences to promote knowledge of the diverse wildlife and habitats of the Namib Desert.

\section{The Gravel Plains}

Less than $30 \mathrm{~m}$ from the Gobabeb entrance gate, the gravel plains extend for hundreds of kilometers and consist of rock substrates in varying dimensions and textures (Wharton and Seely 1982). From a distance, the landscape may seem homogeneous, but the variety of schists, granites, and marbles formed from the Precambrian through the Paleozoic Eras (Viles 2005) supports high reptile diversity, as well as a variety of other African fauna. The two-hour drive from Walvis Bay to Gobabeb almost always includes sightings of Springbok (Antidorcas marsupialis) herds, Ostrich (Struthio camelus), and the inquisitive stares of Bat-eared Foxes (Otocyon megalotis) or the occasional glowing

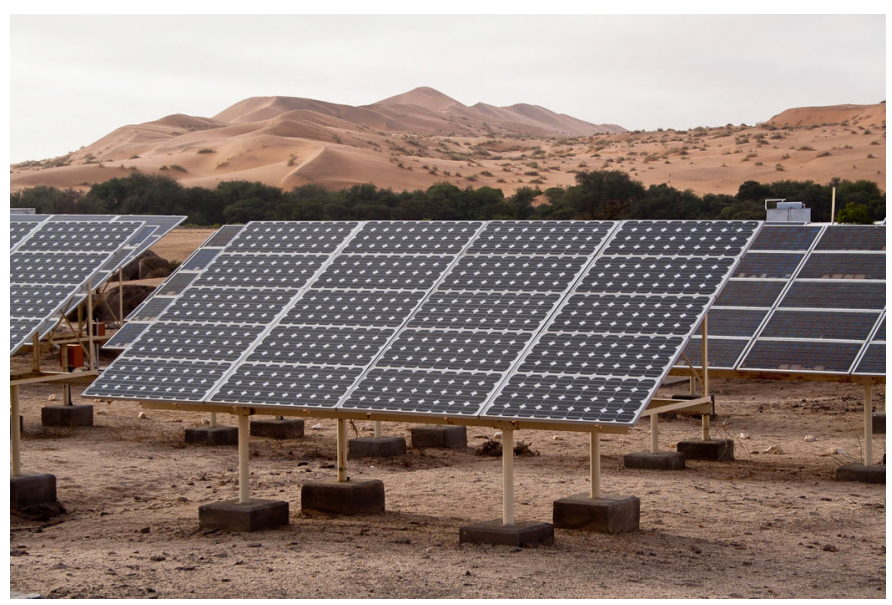

Fig. 3. In a resource-limited environment, sustainable energy is generated by solar panels. 


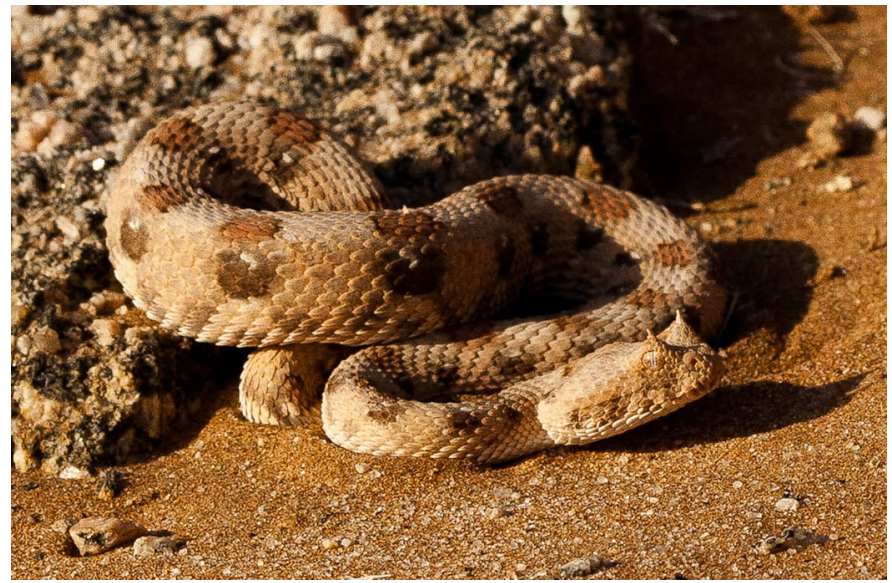

Fig. 4. Horned Adders (Bitis caudalis) are small, heavy-bodied vipers widely distributed across southern Africa. Adders feed largely on vertebrate prey items such as lizards and shrews. The diet of $B$. caudalis varies distinctly with size, sex, and geographic distribution (Shine et al. 1998).

eyes of a Black-backed Jackal (Canis mesomelas) foraging during the evening. Rare encounters include Gemsbok (Oryx gazella), Hartman's Mountain Zebra (Equus zebra hartmannae), or the occasional Aardvark (Orycteropus afer).

\section{Serpents of Gobabeb}

Snakes of the Namib Desert are well adapted for gliding across dunes or compactly fitting into small rock crevices. Fortunately, no deadly venomous snakes occur near the station. The only mildly venomous snakes are adders; the Horned Adder (Bitis caudalis; Fig. 4) may be encountered throughout the gravel plains, whereas the Southern Namib Sand Adder (Bitis peringueyi) may be seen gliding on the dunes. No human fatalities are yet recorded from their bites. Both medium-sized snakes spend most of their diurnal activity hidden in crevices or under shrubs, waiting to ambush prey such as rodents or lizards (Branch 1999). The Horned Adder is commonly seen in its dark red color morph, but occasional individuals are lighter red. In addition, several species of small to large-bodied Sand and Grass Snakes (Psammophis sp.) occur near the station. These comprise a large genus of 23 species found throughout Africa (Branch 1999). Sand Snakes are very fast-moving, active snakes that are difficult to capture and handle. Sometimes, stressed individuals truncate their tails as a defense mechanism (Branch 1999).

\section{Lizards of the Plains}

Gobabeb Centre has a high lizard species diversity. In particular, Sand Lizards (Pedioplanis spp.), including Namaqua Sand Lizards (P. namaquensis) and Spotted Sand Lizards (P. lineoocellata) are commonly observed sprinting rapidly between loose stones in the flat rocky veld. When approaching them in open terrain, they often flee to the nearest rock or burrow. Sand Lizards can be identified largely by their long, slender bodies, long tails relative to overall body length, and

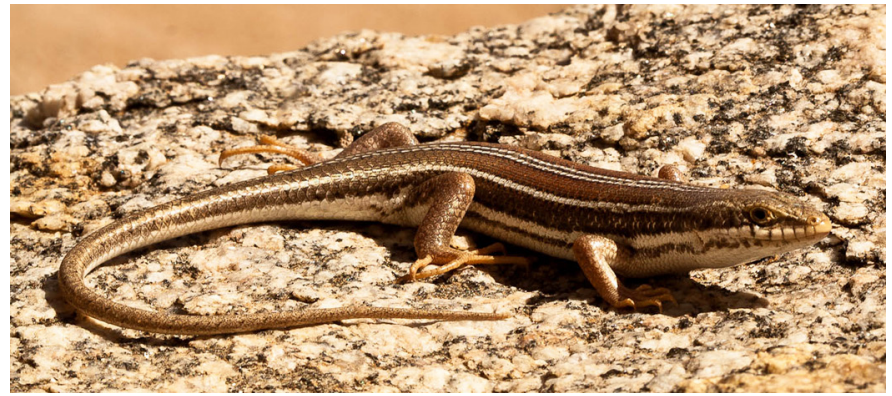

Fig. 5. The Western Three-Striped Skink (Mabuya occidentalis) can be seen near most rocky outcrops, where it actively forages between crevices for arthropod and gekkonid prey.

light brown coloration. Spotted Sand Lizards may actively forage throughout the year, including warm winter days. In contrast, $P$. namaquensis burrows into dormancy during the winter (Branch 1999). Under experimental conditions, $P$. namaquensis was able to recognize the inherent distribution of different kinds of prey insects (Eifler et al. 2012).

We commonly encountered Western Three-Striped Skinks (Mabuya occidentalis, Fig. 5) outside the sparse vegetation surrounding the research library and occasionally even sprinting through our own villa! These hardy skinks vary in coloration from black to red-brown and olive-brown. They hibernate through the winter, but little is known about their reproductive biology (Branch 1999). Unfortunately, we never found a Namaqua Chameleon (Chameleo namaquensis), although others, including local workers, have seen them near Gobabeb. This large-mouthed chameleon is primarily insectivorous, consuming up to 200 beetles daily (Branch 1999). Unlike other chameleons, its tail is much shorter than the overall body length and hardly prehensile.

\section{The Day and Night Shifts}

Gekkonid lizards comprise one of the largest components of the endemic southern African herpetofauna, and the Namib Desert is one of the world's hotspots for gecko diversity (Bauer 1999). The varying terrain facilitates habitat complexity. Peculiar among geckos, Common Namib Day Geckos (Rhoptropus afer, Fig. 6) sprint across large rocks and seek shelter among loose rocks or crevices throughout the day. During male-male interactions, individuals commonly perform push-ups and head-bobbing while competing for territories. Individuals were active on rock substrates when temperatures were over $30^{\circ} \mathrm{C}$. Occupying many of the same rocks are nocturnally active Turner's Thick-Toed Geckos (Chondrodactylus turneri), which have reduced but unique footpads that are well adapted for climbing vertical crevices. Its larger body and darker scales easily distinguish it from $R$. afer.

\section{Scorpion Specialist}

With more than 130 known species (Leeming 2003), southern Africa is one of the world's scorpion hotspots. Not sur- 

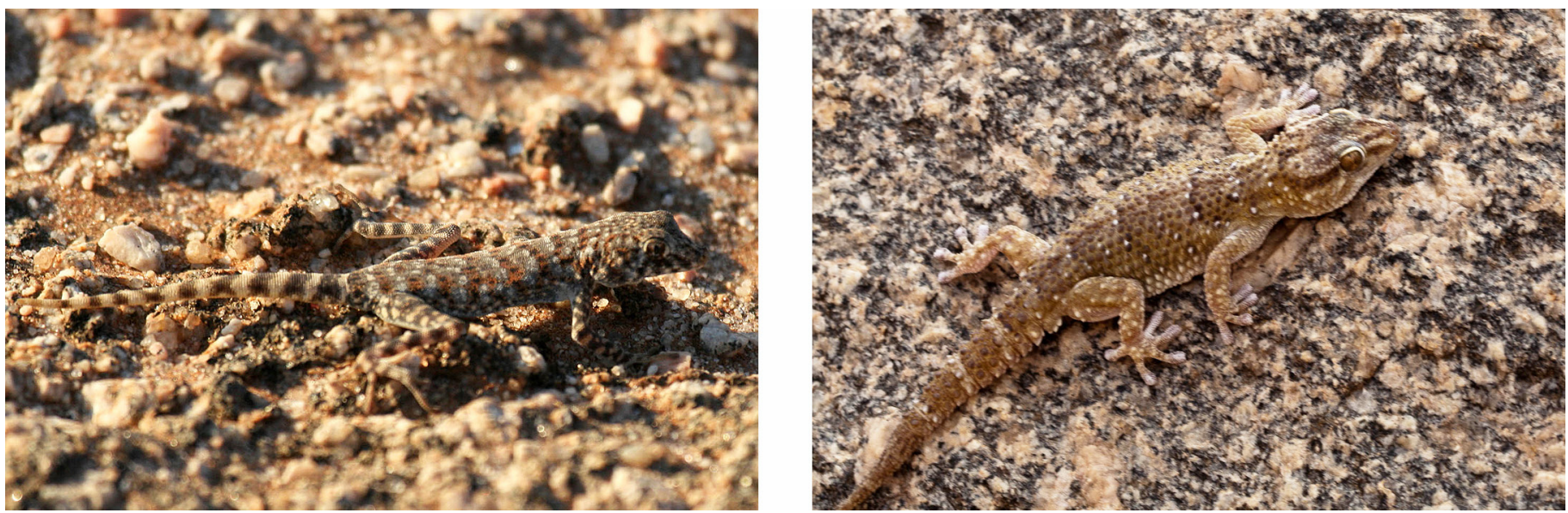

Fig. 6. The Common Namib Day Gecko (Rhoptropus afer, left) is widely distributed throughout the gravel plains. Turner's Thick-Toed Gecko (Chondrodactylus turneri; right) can easily be located at night by its bright eyeshine.

prisingly, Namibia has vertebrates that specialize in capturing and eating these wily and dangerous arachnids (Leeming 2003). We advise visiting researchers to always wear closetoed footwear in the evening and walk with a flashlight to prevent unexpected encounters with scorpions and to be on the alert, even in the shower! The Giant Ground Gecko (Chondrodactylus anguilifer, Fig. 7), an unusually large, cylindrical gecko, is primarily nocturnal and may be found resting in old scorpion burrows during the day (Branch 1999). These gekkonid titans are believed to prey heavily on scorpions. Although we observed only a few individuals, Giant Ground Geckos are highly conspicuous with their large body sizes, vibrant coloration, and stationary defense posture with tailtips slightly bent and limbs raised, they resemble scorpions. Subspecies vary considerably in coloration (brown to pale pink) and even behavioral responses (agonistic biting to rather docile) depending on the locality (Branch 1999).

\section{"Bark, Bark," says the Gecko}

Three species of Barking Gecko (Ptenopus spp.; Fig. 8) call the Namib Desert home. As the name implies, Common Barking
Geckos (P. garrulous), Koch's Barking Geckos (P. kochi), and Carp's Barking Geckos (P. carpi) all have distinct barking calls. For the most part, calls are emitted at the entrances of burrows while bodies are partially emerged. Males have yellow throat patches that they rapidly expand and deflate (Haacke 1964). Common Barking Geckos (P. garrulus) differ from the other two species by being termite specialists and in that males have larger heads than females. In addition, $P$. garrulus digs burrows in loose, deep soil and usually adds branches for structural support (Hibbits et al. 2005).

Koch's Barking Gecko (P. kochi) broadly resembles $P$. garrulus in general appearance. However, upon closer inspection, $P$. koch $i$ is stouter and the yellow pigmentation in males continues beyond the throat, over the mouth region, and down the sides of the body (Branch 1999), although the yellow is bright on the throat and pale elsewhere (Fig 8a). Koch's Barking Gecko is found in the interdune plains (Henschel et al. 2006). In contrast, endemic Carp's Barking Geckos (P. carpi) reside north of the river in the gravel plains, where they burrow in harder soils that usually are mixed with small pebbles (Henschel et al. 2006, Haacke 1964). Distinct from
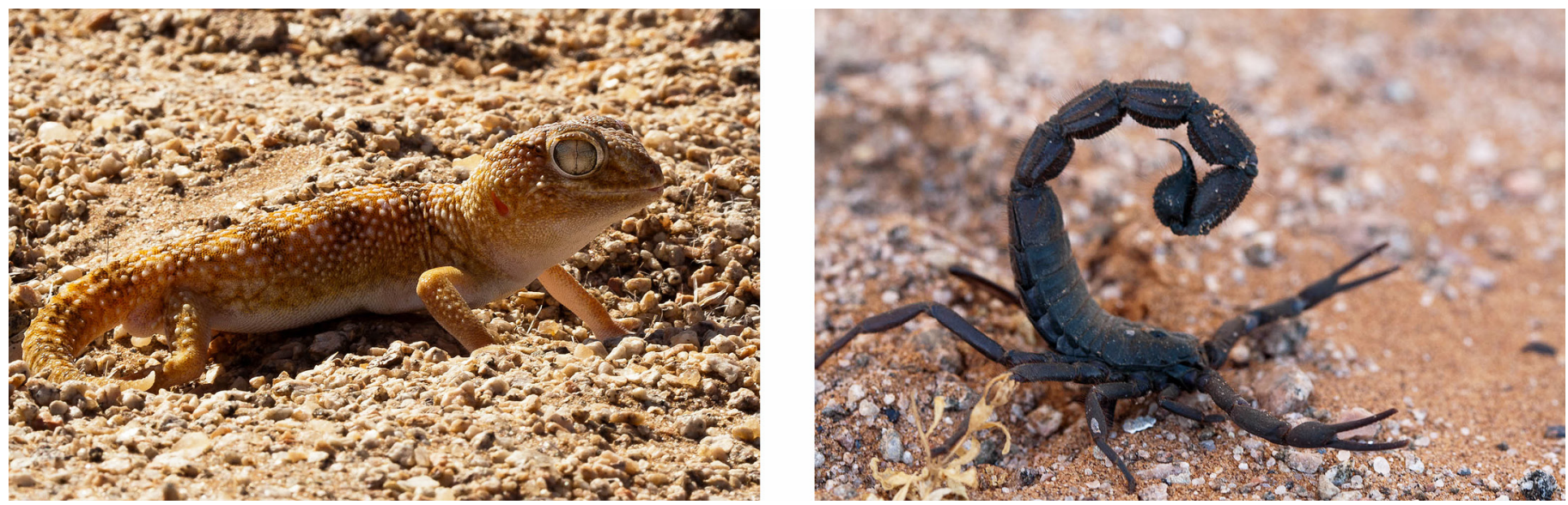

Fig. 7. The Giant Ground Gecko (Chondrodactylus anguilifer, left) likely capitalizes on the scorpion-rich system for prey, although the common Black Hairy Thick-tailed Scorpion (Parabuthus villosus, right) is near fatal for humans and may be a risky meal even for Giant Ground Geckos. 

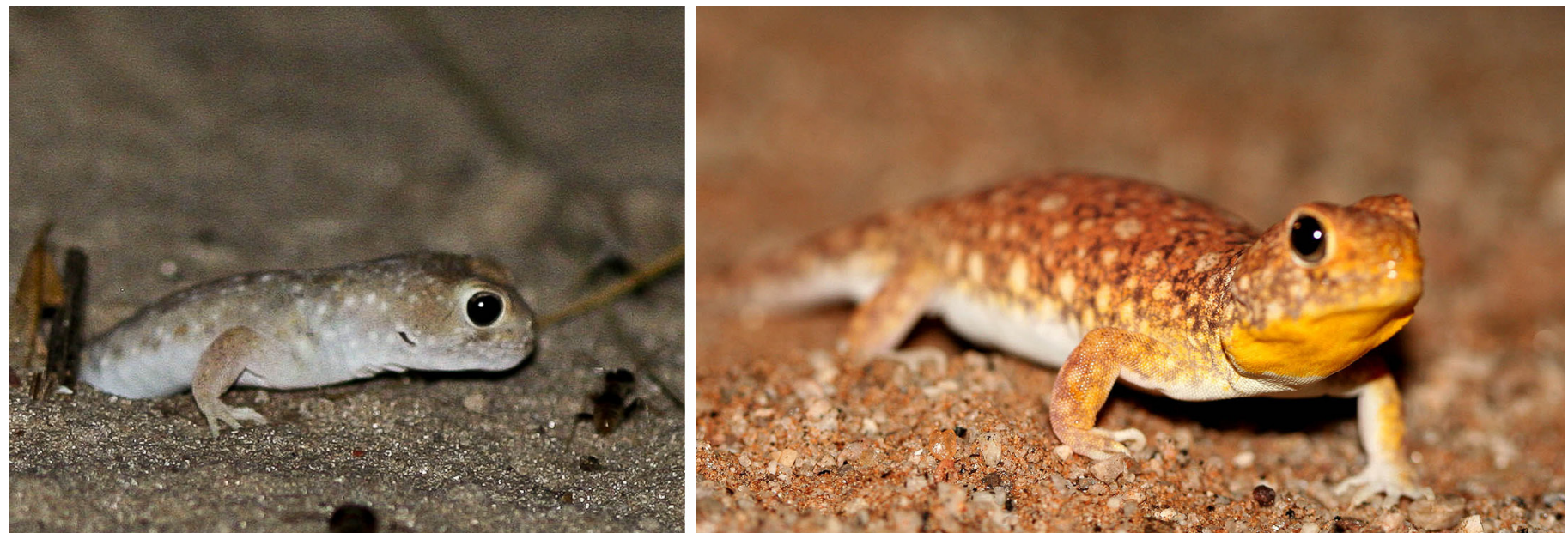

Fig. 8. Both the Common Barking Gecko (Ptenopus garrulous; left) and Koch's Barking Gecko ( $P$. kochi; right) feed on invertebrates and occasionally vegetation. Barking Geckos are the most common nocturnal reptiles in the Namib Desert, where they serve as prey for predatory vertebrates as well as White Lady Spiders (Leucorchestris arenicola; Cloudsley-Thompson 1991).

the other two barking geckos, $P$. carpi has the simplest burrow structure, arguably because of its habitat-specific requirements (Haacke 1964).

\section{Living Dunes}

From a distance the dunes (Fig. 9) appear as mounds of sediment, yet up close they host communities of plants, invertebrates, lizards, snakes, and even some mammals and birds. Beetles and other invertebrates use the small pockets of vegetation as refugia from predators and the heat. In fact, a major source of the soil nitrogen arises from the uric acid waste deposits excreted by beetles (Hadley and Szarek 1981). Even more interesting are the herpetological food-web dynamics. A single dune may host at least three to five different species of lizards along with the occasional Psammophis sand snake and

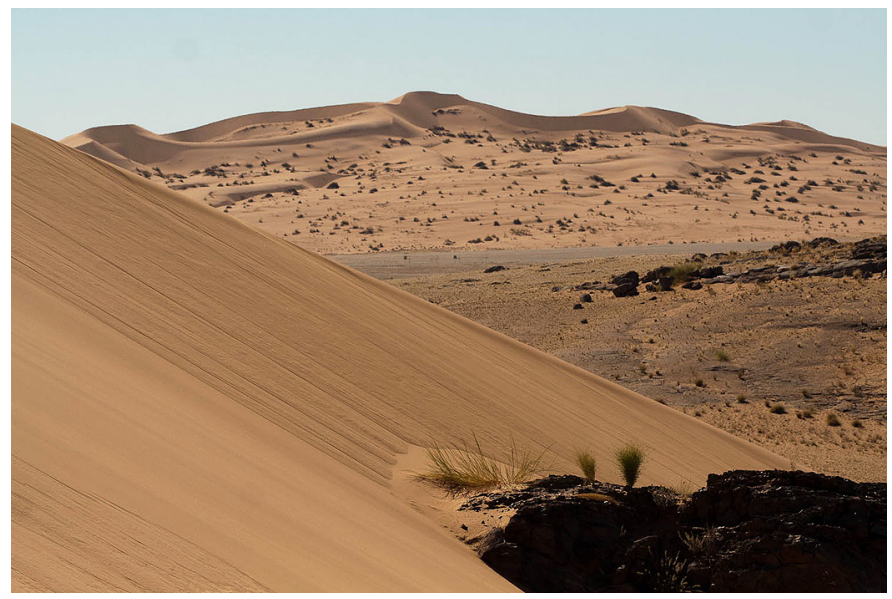

Fig. 9. Strong directional wind patterns in sand-limited environments form half-moon shaped dunes known as barchans. In the Namib Desert, these panoramic dunes can range from a few hundred meters to almost $200 \mathrm{~km}$ in length and from 200 to $300 \mathrm{~m}$ in height (Middleton 2009). If you are observing diurnal lizard activity, leave early in the morning and seek shade before the middle of the day when substrate temperatures can reach well over $35^{\circ} \mathrm{C}$.

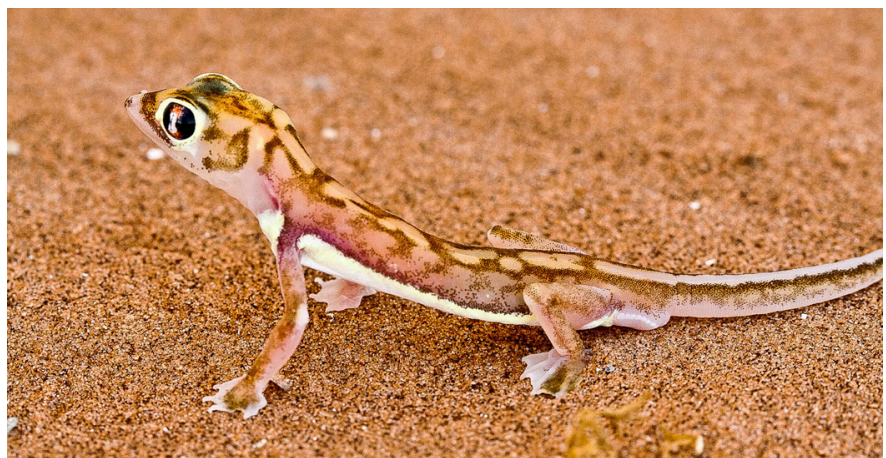

Fig. 10. Namib Dune Geckos (Palmatogecko rangei) are frequently encountered along the dunes in the evening. However, catching these geckos can be rather difficult as they can sprint and dig rapidly through the sand; pursuing them in small groups works well.

adder. For instance, Brain's Blind Legless Skink (Typhlosaurus braini) is a nocturnal lizard that spends its entire life burrowing in sand where it preys on insect larvae and termites (Branch 1999). Despite its commonly visible tracks along the surface of the dunes, our attempts to capture T. braini with pit traps were unfruitful. Little is known about this particular skink, making it a great target for natural history or behavioral research.

\section{Web-footed Gecko}

The Namib Dune Gecko (Palmatogecko rangei; Fig. 10) stands out for its unique life history and specialized morphological adaptations. Even though their appearance is distinct from many other gecko species, they are actually closely related to the Thick-toed Geckos (Chondrodactylus spp.; Branch 1999). The semitransparent, pink-tan coloration of $P$. range $i$ blends with the dunes. Perfectly adapted to arid habitats, they acquire water through fog absorption and the food they consume (Branch 1999). Fog accumulates and the sand is highly compacted from wind and moisture 

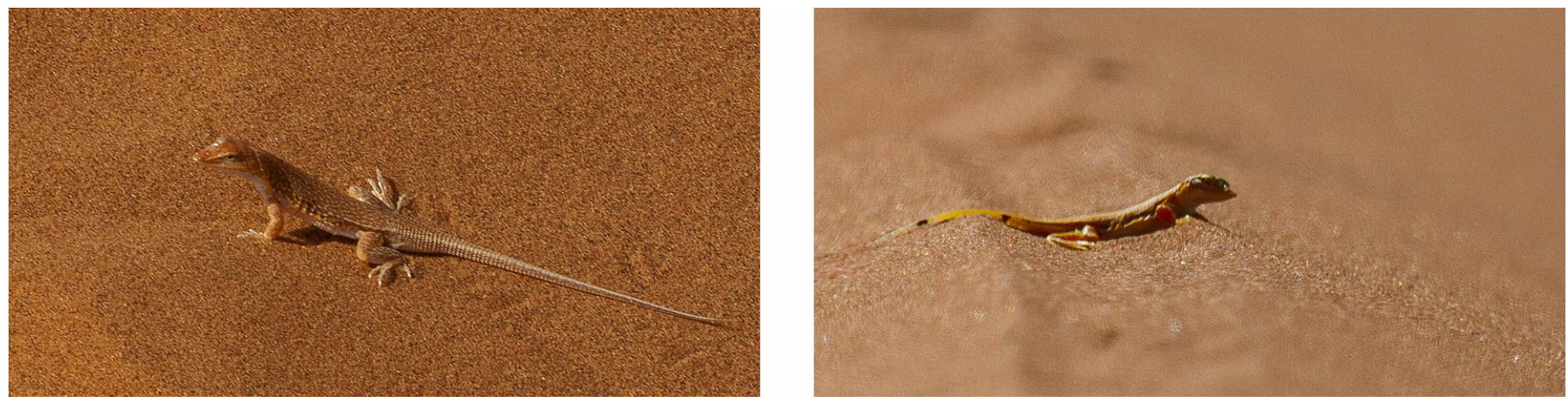

Fig. 11. Both Wedge-snouted Desert Lizards (Meroles cunirostris, left) and Shovel-snouted Lizards (M. anchietae, right) dive into sand to escape predators. Patchy vegetation on the dunes is an oasis for biological activity, as lizards forage in the brush for arthropods while snakes search for lizards.

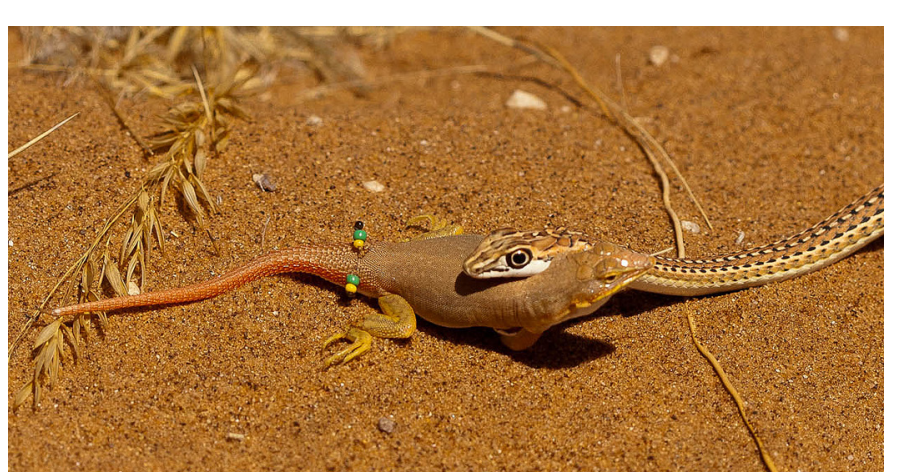

Fig. 12. The Wedge-snouted Desert Lizard (Meroles cunirostris; left) is a common prey item for the Cape Sand Snake (Psammophis leightoni) on the lower stretches of the dunes. The colored beads are from a previous mark-recapture study.

at the lower bases of dunes where they occur, (Russell and Bauer 1990). Their distinctive webbed toepads, which likely emerged as their claws were reduced over evolutionary time, not only function as snowshoe-like morphological structures for gliding along the sand, but they can also serve as shovels for sifting through sand during burrow construction (Russell and Bauer 1990). Amazingly, the span of their feet can reach $236^{\circ}$, providing them with the greatest digital span of all reptiles known to man (Russell and Bauer 1990)!

\section{Shovel versus Wedge}

The Shovel-snouted Lizard (Meroles anchietae) and the Wedge-snouted Lizard (Meroles cuneirostris) are closely related phylogenetically but vary distinctly in their morphology (Fig. 11). The common names reflect the shapes of their heads. Additionally, M. anchiteae (SVL: $\mathrm{M}=49 \mathrm{~mm}$ and $\mathrm{F}=44 \mathrm{~mm}$ ) are on average smaller than $M$. cuneirostris (SVL: $\mathrm{M}=54 \mathrm{~mm}$ and $\mathrm{F}=49 \mathrm{~mm}$; Goldberg and Robinson 1979). Their snouts and long, thin hindlegs allow them to maneuver quickly through sand to escape deadly heat and abundant predators (Branch 1999). Wedge-snouted Lizards (M. cuneirostris; Fig. 12) occupy the lower bases of the sand dunes, frequently near the Kuiseb riverbed. They often forage in the interdune plains, where the habitat is flat, sandy, and vegetated, and are host to a variety of insects (Goldberg and Robinson 1979). In contrast, $M$. anchietae is primarily found on steep slopes of the dunes where vegetation is minimal. Their diet consists mainly of two species of arthropods and seeds that are dispersed by the wind (Goldberg and Robinson 1979). However, both of these lacertids exhibit high-speed locomotion across sand via the fringed toes, a mechanism providing for both thermal regulation and predator avoidance (Branch 1999). Apparently, the advantage of a shovel- or wedge-shaped snout relies on the distinct sandy microhabitats of the dunes.

\section{Discussion}

Overall, The Gobabeb Research and Training Centre is a prime research facility for fieldwork not only because of its high reptile diversity, but also due to its strong emphasis on collaboration and sustainability - conserving water and exploiting sunlight for electricity in a fragile landscape. We highly recommend a brief visit to Gobabeb to view and learn

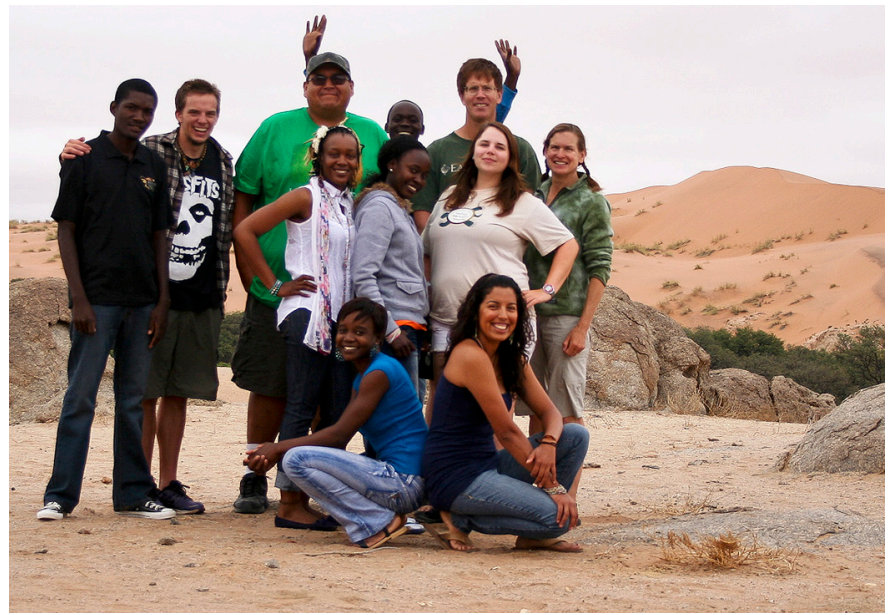

Fig. 13. The Erell Institute hosted a motley crew of wildlife enthusiasts, eager to learn about the herpetofauna of the Namib Desert. Students represented many nations: Botswana, Cherokee, Cheyenne, Chickasaw, Hopi, Namibia, Three Affiliated Tribes, and Yaqui. "Education is your greatest weapon. I do not think the measure of a civilization is how tall its buildings of concrete are, but rather how well its people have learned to relate to their environment and fellow man." - Sun Bear (Chippewa). 
about their progressive approach to sustainability, experience their welcoming community, and immerse yourself in the region's unique biodiversity.

\section{Acknowledgements}

We are grateful to the efficient and accommodating staff and administration of the Gobabeb Research and Training Centre. The National Science Foundation provided funding for travel, research supplies, and stipends. The Erell Institute organized this undergraduate research experience while fostering life-long connections for indigenous students from the United States, Namibia, and Botswana (Fig. 13).

\section{Literature Cited}

Cloudsley-Thopmpson, J.L. 1991. Interspecific relationships, feeding specializations and species diversity. Ecophysiology of Desert Arthropods and Reptiles 1991:147-168.

Branch, B. 1999. A Field Guide to Snakes and Other Reptiles of Southern Africa. 3rd ed. Struik Publishers, Cape Town.

Bauer, A.M. 1999. Evolutionary scenarios in the Pachydactylus group geckos of southern Africa: New hypotheses. Africa Journal of Herpetology 48:53-62.

Edney, E.B. 1971. Some aspects of water balance in tenebrionid beetles and a thysanuran from the desert of southern Africa. Physiological Zoology 44:61-67.

Eifler, D.A., K. Baipidi, M.A. Eifler, D. Dittmer, and L. Nguluka. 2012. Influence of prey encounter and prey identity on area-restricted searching in the lizard Pedioplanis namaquensis. Journal of Ethology 30:197-200.

Goldberg, S.R and M.D. Robinson. 1979. Reproduction in two Namib Desert lacterid lizards (Aporosaura anchietae and Meroles cuneirostris). Herpetologica 35:169-175.

Goldblatt, P. and J.C. Manning. 2002. Plant diversity of the Cape region of southern Africa. Annals of Missouri Botanical Garden 89:281-302.

Haacke, W.D. 1964. Description of two new species of lizards and notes on Fitzsimonsia brevipes (Fitzsimons) from the central Namib Desert. Scientific Papers of Namib Desert Research Station 25:1-15.

Hadley, N.F. and S.R. Szarek. 1981. Productivity of desert ecosystems. BioScience 31:747-753.

Henschel, J.R., J. Pallett, C. Berry, M. Griffin, B. Hachfeld, O. Makuti, and M.K. Seely. 2006. Checklists of the flora and vertebrates of Gobabeb. Journal of Namibia Scientific Society 54:31-56.

Hibbits, T.J., E. Pianka, R.B. Huey, and M.J. Whiting. 2005. Ecology of the Common Barking Gecko (Ptenopus garrulus) in southern Africa. Journal of Herpetology 39:509-515.

Leeming, J. 2003. Scorpions of Southern Africa. Struik Nature, Random House Struik (Pty) Ltd., Cape Town.

Middleton, N. 2009. Deserts: A Very Short Introduction. Oxford University Press, New York.

Russell, A. and A.M. Bauer. 1990. Substrate excavation in the Namibian Webfooted Gecko, Palmatogecko rangei Andersson 1908, and its ecological significance. Tropical Zoology 3:197-207.

Shine, R., W.R. Branch, P.S. Harlow, and J.K. Webb. 1998. Reproductive biology and food habits of Horned Adders, Bitis caudalis (Viperidae), from southern Africa. Copeia 1998:391-401.

Schulze, B.R. 1969. The climate of Gobabeb. Scientific Papers of Namib Desert Research Station 38:5-12.

Viles, H.A. 2005. Microclimate and weathering in the central Namib Desert, Namibia. Geomorphology 67:189-209.

Wharton, R.A. and M.K. Seely. 1982. Species composition of and biological notes on Tenebrionidae of the lower Kuiseb River and adjacent gravel plain. Madoqua 13:5-25. 